\title{
Metallurgy and material|s
}

http://dx.doi.org/10.1590/0370-44672014680189

\author{
Bruna Horta Bastos Kuffner \\ Mestranda em Engenharia de Materiais, \\ Universidade Federal de Itajubá - UNIFEI, \\ Instituto de Engenharia Mecânica \\ Itajubá - Minas Gerais - Brazil \\ brunakuffner@hotmail.com

\section{Wellington Silvio Diogo \\ Doutorando em Materiais para Engenharia, Universidade Federal de Itajubá - UNIFEI, Instituto de Engenharia Mecânica \\ Itajubá - Minas Gerais - Brazil \\ wsdiogo@hotmail.com}

\section{Daniel Assis Amancio \\ Doutorando em Engenharia Mecânica, Universidade Federal de Itajubá - UNIFEI, Instituto de Engenharia Mecânica \\ Itajubá - Minas Gerais - Brazil \\ daniel_assis_amancio@hotmail.com}

\section{Geovani Rodrigues}

Professor Doutor em Engenharia de Materiais, Universidade Federal de Itajubá - UNIFEI, Instituto de Engenharia Mecânica Itajubá - Minas Gerais - Brazil grodrigues@unifei.edu.br

\section{Gilbert Silva}

Professor Doutor em Engenharia Biomédica, Universidade Federal de Itajubá - UNIFEI, Instituto de Engenharia Mecânica Itajubá - Minas Gerais - Brazil gilbert@unifei.edu.br

\section{Introduction}

The AISI 52100 is a high carbon, chrome, and manganese steel which finds applications in bearings due to its high strength and resistance to rolling contact fatigue (Li \& Wang, 1993; Umbrello et al., 2004). In their service life, bearings

\section{Evaluation of the milling efficiency increase of AISI! 52100 steel using niobium carbide addition through high energy ball milling}

\begin{abstract}
The AISI 52100 is a tool-type steel and is more often used in industry for the production of bearings. After the end of its life cycle, it is discarded or remelted, but both processes are considered expensive. Thus, the possibility of reusing this material through the powder metallurgy (PM) route is considered advantageous, since it transforms a waste into another product. To obtain the starting powders, the AISI 52100 steel scrap was submitted to a process of high energy ball milling, which was milled pure and with 1 and $3 \%$ of niobium carbide $(\mathrm{NbC})$ additions. Those additions were performed with the intention of increasing the milling efficiency of the steel, through formation of a metal-ceramic composite with a ductile-fragile behaviour. To determine the morphology and particle size, scanning electron microscopy (SEM) and particle size distribution tests were used. The results indicated that with the carbide addition, a significant increase in the milling efficiency was achieved, being possible to obtain nanoparticles after 20 hours of milling time.
\end{abstract}

Keywords: AISI 52100 steel; high energy ball milling; carbide; nanoparticle.

are subjected to complex multi-axial stress states that change periodically in combination with high operational temperatures (Chakraborty et al., 2009; Young $\&$ Badeshia, 2004). They must sustain relatively large contact stresses during the extremely high number of cycles that are submitted (Dommarco et al., 2004; Christ et al., 1992). One of the methods to increase the resistance of bearings produced by AISI 52100 steel is through powder metallurgy (Rhee et al., 2007). 
Powder metallurgy is a promising route widely used to produce highstrength steels for the fabrication of pieces with complex shapes with less material waste (German, 1998; Esper \& Sonsino, 1996). These steels show several important properties, such as high mechanical strength and wear resistance (Selvakumar et al., 2012; Lane \& Smith, 1982). However, they usually possess residual porosity and a heterogeneous microstructure (Narasimhan, 1996). The porosity has been shown to significantly influence the fatigue response of steels (Hadrboletz \& Weiss, 1997).

To improve the mechanical properties of steels produced by powder metallurgy, the creation of a metal-ceramic

\section{Materials and Methods}

The material used in this research was the AISI 52100 steel from the process of hot rolling as a round bar, the same material used to produce bearings. This workpiece had $100 \mathrm{~mm}$ of diameter and passed through the step of machining at slow speed and without the use of lubrica-

tion to avoid oxygen and oil-soluble contamination. With the procedure described, it was possible to obtain the AISI 52100 steel in the form of scraps, which were used subsequently in the milling process.

The scraps were milled pure and with $1 \%$ and $3 \%$ of $\mathrm{NbC}$ addition

\begin{tabular}{|c|c|c|c|}
\hline Composition & Material & $\begin{array}{l}\text { AISI } 52100 \\
\text { weight (g) }\end{array}$ & $\begin{array}{c}\mathrm{NbC} \\
\text { weight(g) }\end{array}$ \\
\hline 1 & AISI 52100 & 30 & 0 \\
\hline 2 & $\begin{array}{l}\text { AISI } 52100 \\
+1 \% \mathrm{NbC}\end{array}$ & 29.7 & 0.3 \\
\hline 3 & $\begin{array}{l}\text { AISI } 52100 \\
+3 \% \mathrm{NbC}\end{array}$ & 29.1 & 0.9 \\
\hline
\end{tabular}

The characterization of the raw materials and their compositions was realized using a scanning electron microscope Carl Zeiss EVO MA15. In the second-

\section{Results and Discussion}

The initial characterization of the AISI 52100 steel scraps and the niobium carbide are shown in Figures 1 and 2. It can be observed that the AISI 52100 composite with carbide addition as reinforcement is advantageous (Trueman et al., 1999). The concentration of this reinforcement in such composites is typically less than $50 \%$ in volume (Lu et al., 2012; Eigen et al., 2003; Yusop et al., 2009).

Carbides are compounds formed by carbon and metal atoms. The metal carbides present important properties, such as a very high melting point (close to $4000^{\circ} \mathrm{c}$ ), great hardness, and good electric and thermal conductivity (Gubernat \& Zych, 2014; Kosolapova, 1971). The niobium carbide $(\mathrm{NbC})$ presents interesting characteristics for its use in wear applications, such as great hardness, great toughness, extremely high young's modulus and high melting temperature ary electron (SE) mode, the particle size variation and morphology were analyzed. Using the back scatter electron (BSD) and energy dispersive x-ray (EDS) modes, steel scraps from the machining process showed a mean size of $1200 \mu \mathrm{m}$ (Figure 1).

Figure 2 shows the microphoto- $\left(3873^{\circ} \mathrm{c}\right.$ ) (Amriou et al., 2003; Sustarsic et al., 2001).

In powder metallurgy, the powders pass through the steps of milling, cold pressing and sintering. Using high energy ball milling, it's possible to produce nanoparticles, which consequently, increase the densification, decrease the porosity in sintered materials and improve the mechanical resistance of the product (Wang \& Jiang, 2007). The high energy ball milling utilizes high frequency and high energy impacts from the milling balls to repeatedly forge powder particles together, which causes a greater reduction in the particle's size in comparison with traditional milling (Lu \& Lai, 1998; Suryanarayana, 2001).

(Table 1). The milling was realized using high energy ball milling in a planetary ball mill during the milling times of 5, 10, 15 and 20 hours in an inert argon atmosphere to avoid oxidation of the powders, at a milling speed of $350 \mathrm{rpm}$ and a mass/sphere relationship of 1:10.

Table 1

Mixtures composition

the carbide distribution was evaluated. Particle size distribution was performed in a Malvern Mastersizer 2000 particle size analyzer.

graph of $\mathrm{NbC}$. In this figure, it is possible to note that the particles presented heterogeneous granulometry varying from 1 to $5 \mu \mathrm{m}$. 
Figure 1 AISI 52100 steel scrap

Figure 2 $\mathrm{NbC}$ powder

It can be observed in Figure $3 a$ that after 5 hours of milling, the scrap of the pure AISI 52100 steel maintained its morphology and dimension
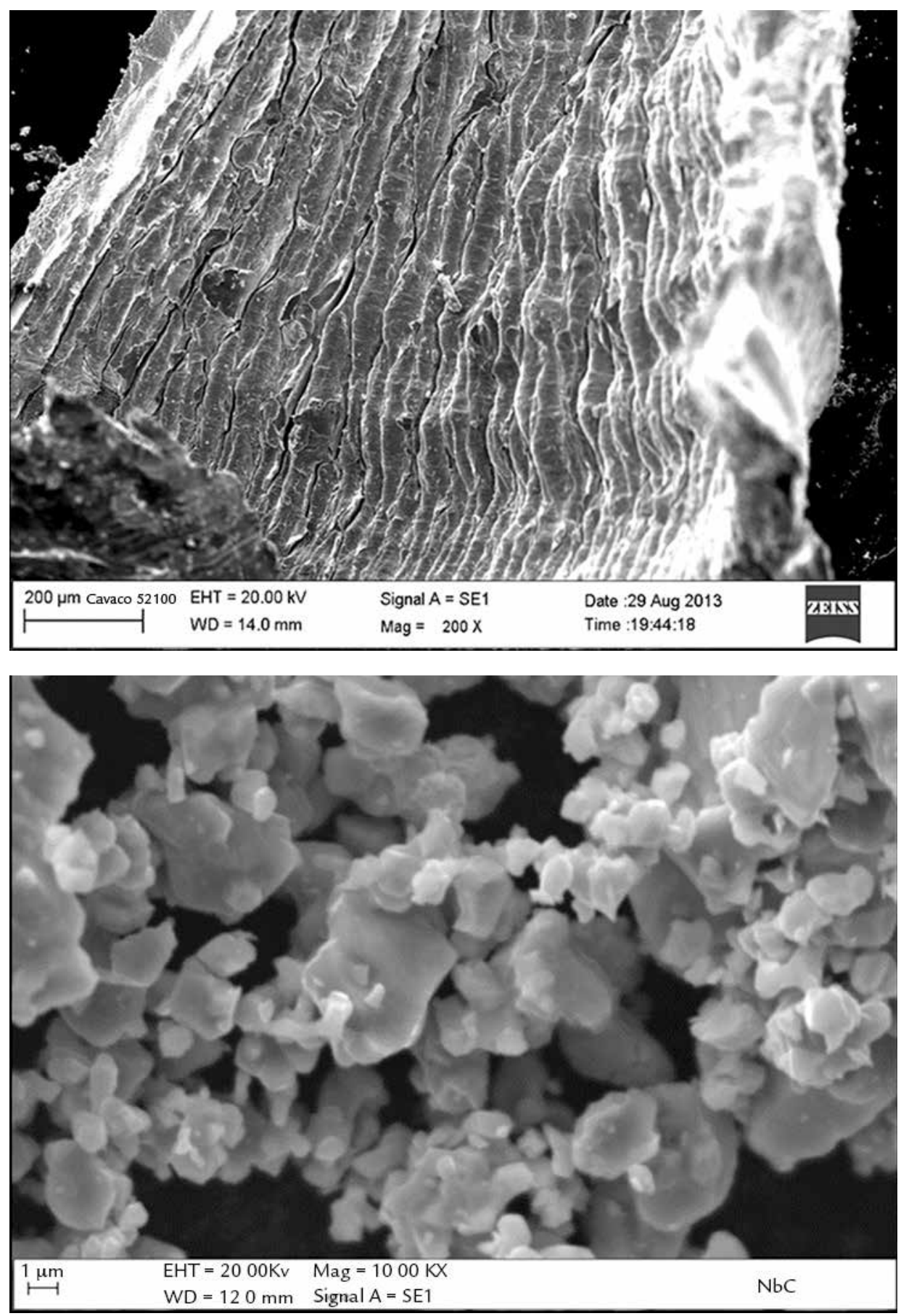

in comparison with the scrap before the milling process (Figure 1). By increasing the milling time to 20 hours, the scraps of the AISI 52100 steel were transformed into particles with angular morphology and medium-sized particles located between 5 and $40 \mu \mathrm{m}$ as shown in Figure $3 b$.
Figure 3

Pure AISI 52100 steel milled for (a) 5 hours (b) 20 hours
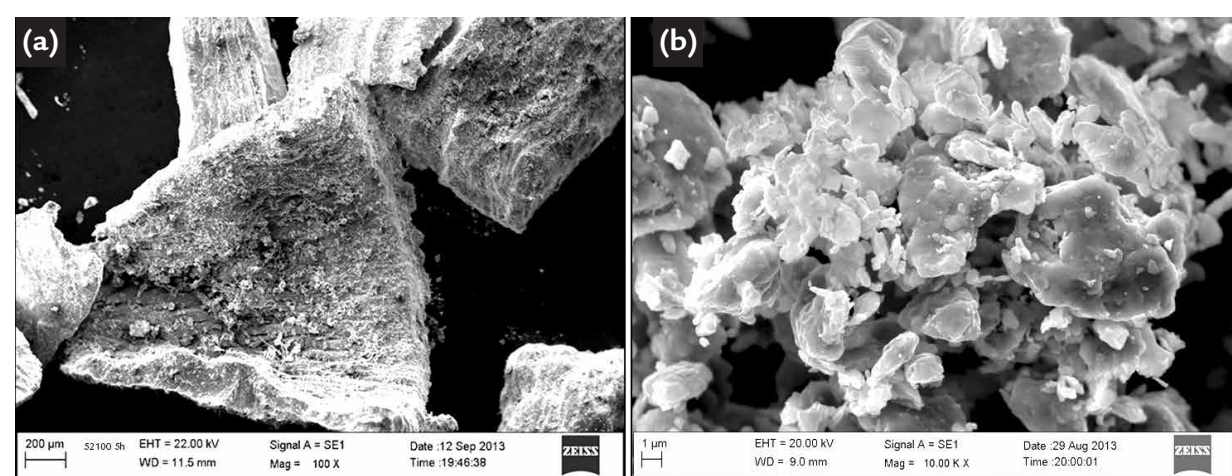
By performing the milling of the AISI 52100 steel scraps for 5 hours and with a $1 \%$ of $\mathrm{NbC}$ addition, it was possible to obtain particles with a flaky morphology and sizes between 20 and $200 \mu \mathrm{m}$ (Figure 4a), however, with a large volume of smaller par-

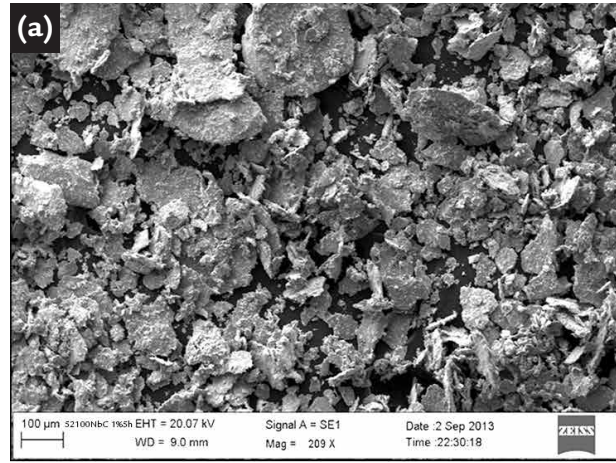

When milling the AISI 52100 steel for 5 hours with a $3 \% \mathrm{NbC}$ addition, it was observed that there was no change in the particle morphology. However, noted was a significant reduction in the particles size of the AISI 52100 steel in comparison

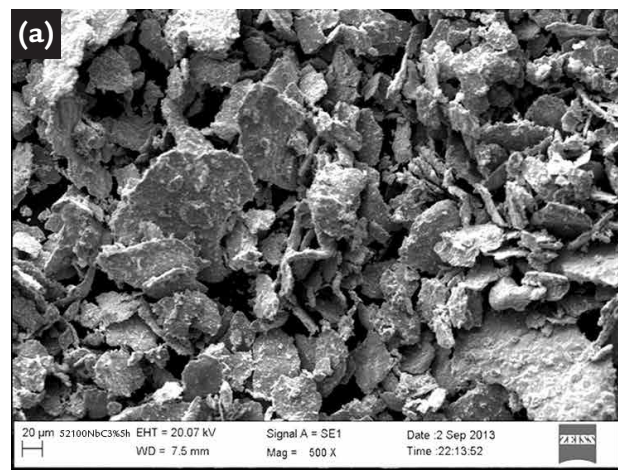

The carbide distribution was evaluated under the scanning electron microscope (SEM) using the energy dispersive x-ray (EDS) mode (Figure 6). It was ob-

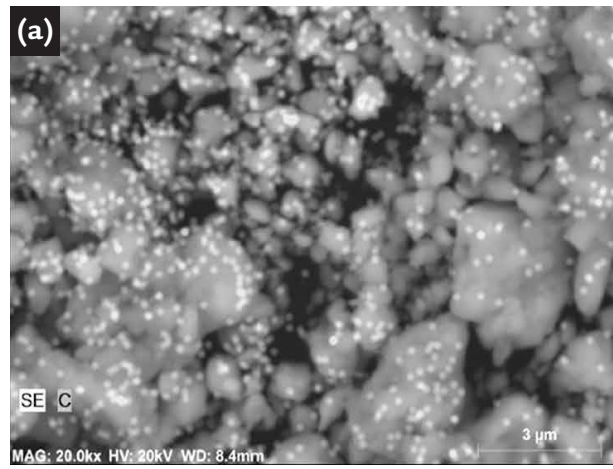

The results of the particle size distribution test are shown in Figure 7. It is possible to observe that the curve presented a bimodal distribution. When milled with the niobium ticles. When maintaining the $\mathrm{NbC}$ percentage at $1 \%$ and continuing the milling of the AISI 52100 steel for 20 hours, it was possible to observe the formation of clusters with a dimension around $20 \mu \mathrm{m}$ and the presence of nanoparticles (Figure 4b). Thus,

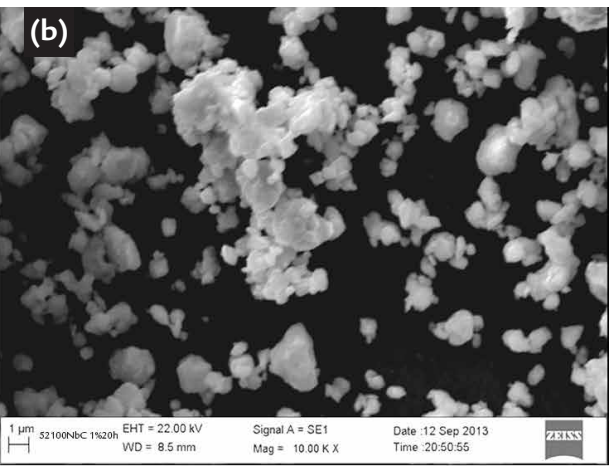

with the milling process using $1 \%$ of $\mathrm{NbC}$ addition (Figure $4 \mathrm{a}$ ). In this condition, the particles present sizes between 20 and $170 \mu \mathrm{m}$ (Figure 5a). Maintaining the $\mathrm{NbC}$ percentage at $3 \%$ and milling during 20 hours, the AISI 52100 steel

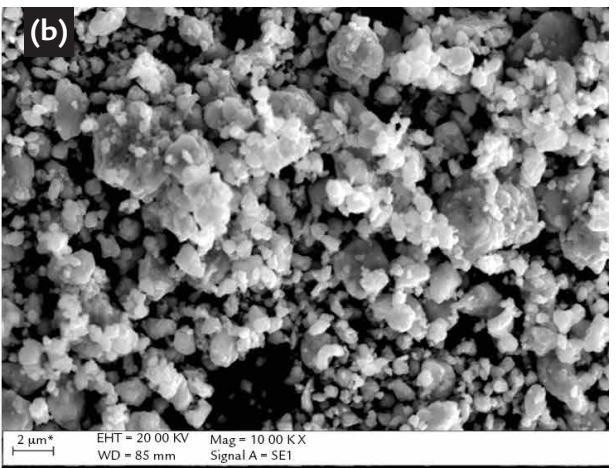

served that the $\mathrm{NbC}$ particles were located homogeneously on the surface of the steel particles. The NbC particles were identified in Figure 6 by its chemical elements

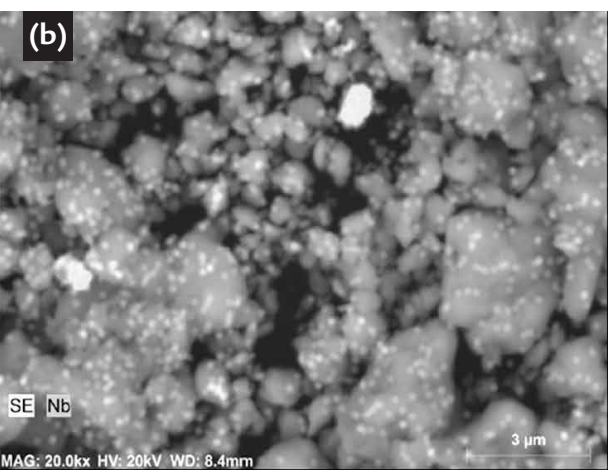

carbide addition, the steel particles presented greater volume in the range of $1 \mathrm{~nm}$ up to $4 \mathrm{~nm}$ and that of 10 $\mathrm{nm}$ up to $40 \mathrm{~nm}$. When milled without $\mathrm{NbC}$ addition, the steel particles comparing the milling process of the pure AISI 52100 steel with a $1 \%$ of $\mathrm{NbC}$ addition, under the same milling condition, a significant reduction in the obtained particles was observed, demonstrating an increase in the milling process efficiency.

Figure 4

AISI 52100 steel with $1 \%$ of $\mathrm{NbC}$ addition milled for (a) 5 hours (b) 20 hours

formed clusters with approximately 300 $\mu \mathrm{m}$ with medium-sized particles located in nanometric scale (Figure $5 \mathrm{~b}$ ). In addition, a greater homogeneity was observed in the nanoparticle volumes when compared to the steel milled with $1 \%$ of $\mathrm{NbC}$.

Figure 5

AISI 52100 steel with $3 \%$ of $\mathrm{NbC}$ addition milled for (a) 5 hours (b) 20 hours

(C and $\mathrm{Nb}$ ). In Figure $6 \mathrm{a}$, the brighter dots represent the carbon element, and in Figure $6 \mathrm{~b}$, the brighter dots represent the niobium element.

Figure 6

Identification of the $\mathrm{NbC}$ chemical elements (a) Carbon (b) Niobium

presented a greater volume in the range of $2 \mathrm{~nm}$ up to $80 \mathrm{~nm}$ and that of $100 \mathrm{~nm}$ up to $200 \mathrm{~nm}$, showing an increase in the milling efficiency with the carbide addition. 
Figure 7

AISI 52100 steel particles size distribution without and with $3 \%$ of $\mathrm{NbC}$ addition

\section{Conclusions}

When using the high energy ball milling process, it was possible to obtain powders of the pure AISI 52100 steel and

\section{Acknowledgements}

This work was financially supported by CNPq and FAPEMIG. We would also like to thank the compa-

\section{References}

also those with $\mathrm{NbC}$ additions. However, with the $\mathrm{NbC}$ additions, it was observed that there was a significant increment in the milling efficiency, which enabled the obtainment of powders close to the nanometric scale. nies Villares Metals and Hermann C. Stark for the material donations and the UNIFEI characterization's laboratory technicians for the technical support.

AMRIOU, T., BOUHAFS, B., AOURAG, H., KHELIFA, B., BRESSON, S., MATHIEU, C. FP-LAPW investigations of electronic structure and bonding mechanism of $\mathrm{NbC}$ and $\mathrm{NbN}$ compounds. Physica B: Condensed Matter, v. 325, p. 46-56, 2003.

CHAKRABORTY, J., BHATTACHARJEE, D., MANNA, I.A. Development of ultrafine bainite + martensite duplex microstructure in SAE 52100 bearing steel by prior cold deformation. Scripta Materialia, v. 61, n. 6, p. 604-607, 2009.

CHRIST, H. J., SOMMER, C., MUGHRABI, H., VOSKAMP, A.P., BESWICK,J.M., HENGERER, F. Fatigue behaviour of three variants of the roller bearing steel SAE 52100. Fatigue \& Fracture of Engineering Materials\& Structures, v. 15, n. 9, p. 855-870, 1992.

DOMMARCO, R. C., KOZACZEK, K.J., BASTIAS, P.C., HAHN, G.T., RUBIN, C.A. Residual stresses and retained austenite evolution in SAE 52100 steel under non-ideal rolling contact loading. Wear, v. 257, n. 11, p. 10811088, 2004.

EIGEN, N., KLASSEN, T., AUST, E., BORMANN, R., GARTNER, F. Production of nanocrystalline cermet thermal spray powders for wear resistant coatings by high energy milling. Materials Science and Engineering A, v. 356, n. 1-2, p. 114-121, 2003.

ESPER, F. J., SONSINO, C. M. Fatigue design for PM components: Manual for design and production engineers. International Journal of Fatigue, v. 18, n. 2, p. 149, 1996.

GERMAN, R. M. Powder metallurgy of iron and steel. New York: John Wiley \& Sons, 1998. 496p.

GUBERNAT, A., ZYCH, L. The isothermal sintering of the single-phase non-stoichiometric niobium carbide ( $\mathrm{NbC1}-\mathrm{x})$ and tantalum carbide $(\mathrm{TaC} 1-\mathrm{x})$. Journal of the European Ceramic Society, v. 34, p. 2885-2894, 2014. 
HADRBOLETZ, A., WEISS, B. Fatigue behavior of iron based sintered material: A review. International Materials Review, v. 42, n. 1, p. 1-44, 1997.

KOSOLAPOVA, T. Y. Carbides properties, production and applications. New York: Springer Publishing, 1971. 316p.

LANE, M. S., SMITH, P. Developments in sintered valve seat inserts. Metal Powder Report, v. 1, p. 474-480, 1982.

LI, C., WANG, J. L. Effect of pre-quenching on martensite-bainitic microstructure and mechanical properties of GCr15 bearing steel. Journal of Material Science, v. 28, n. 8, p. 2112-2118, 1993.

LU, L., LAI, M. O. Mechanical Alloying. Boston: Kluwer Academic Publishers, 1998. 276p.

LU, Z. J., SHEN, Y.F., GU, D.D. Synthesis and characterization of Si3N4P/Cu nanocomposite powders by high energy ball milling. Powder Metallurgy, v. 53, p. 86-90, 2010.

NARASIMHAN, K. S. Recent advances in ferrous powder metallurgy. Advanced Performance Materials, v. 3, p. 7-27, 1996

RHEE, S. I., NAM, S. W., HAGIWARA, M. Effect of TiBp particle reinforcement on the creep resistance of near a titanium alloy made by blended elemental powder metallurgy. Journal of Alloys and Compounds, v. 359, n. 1-2, p. 186-192, 2003.

SELVAKUMAR, N., MOHAN, A.R., NARAYANASAMY, R. Experimental investigation on workability and strain hardening behavior of $\mathrm{Fe}-\mathrm{C}-0.5 \mathrm{Mn}$ sintered composites. Materials and Design, v. 41, p. 349-357, 2012.

SURYANARAYANA, C. Mechanical alloying and milling. Progress in Materials Science, v. 46, n. 1-2, p.1-184, 2001.

SUSTARSIC, B., JENKO, M., GODEC, M., KOSEC, L. Microstructural investigation of $\mathrm{NbC}$-doped vacuum-sintered tool-steel-based composites.Vacuum, v. 71, n. 1-2, p. 77-82, 2003.

TRUEMAN, A. R., SCHWEINSBERG, D.P., HOPE, G.A.A study of the effect of cobalt additions on the corrosion of tungsten carbide/carbon steel metal matrix composites.Corrosion Science, v. 41, n. 7, p. 1377-1389, 1999.

UMBRELLO, D HUA, J., SHIVPURI, R. Hardness-based flow stress and fracture models for numerical simulation of hard machining AISI 52100 bearing steel. Materials Science and Engineering A, v. 374, n. 1-2, p. 90-100, 2004.

WANG, L. L., JIANG, J. S. Preparation of a- $\mathrm{Fe}_{2} \mathrm{O}_{3}$ nanoparticles by high-energy ball milling. Physica B, v. 390, n. 1-2, p. 23-27, 2007.

YOUNG, C. H., BADESHIA, H.K.D.H. The strength of mixtures of bainite and martensite. Materials Science and Technology, v. 10, p. 209-214, 1994.

YUSOP, M., ZHANG, D., WILSON, M. Microstructure and magnetic properties of nanostructured Al2O3-20 vol.\% Fe70Co30 composite prepared by high energy mechanical milling. International Journal of Modern Physics B, v. 23, n. 6-7, p. 1383-1388, 2009.

Received: 19 September 2014 - Accepted: 10 June 2015. 